\title{
Influence of the Learning Model Using a Geogebra - Based Software on the Potential Mathematical Problem Based on a Self Confidence Student on the Cone Slices
}

\author{
John N. Lekitoo ${ }^{1, *}$ Tanwey G. Ratumanan ${ }^{2}$, Carolina S. Ayal ${ }^{3}$ \\ 1,2, ${ }^{3}$ Magister Education of Mathematics, Univesity of Pattimura \\ *Corresponding author. Email: johnlekitoo@gmail.com
}

\begin{abstract}
This study aims to: (1) determine whether there is a difference in the mathematical solving abilities of students of class XI MIA SMA Negeri 4 Ambon who are taught using the think pair share (TPS) type of cooperative learning model assisted by geogebra software, the problem based learning model (PBL) with software assistance. geogebra, and discovery learning (DL) learning model assisted by geogebra software, (2) knowing whether there are differences in the mathematical problem solving abilities of class XI MIA students of SMA Negeri 4 Ambon who have high selfconfidence, moderate self-confidence, and low self confidence, and (3) knowing whether there is an effect of interaction between cooperative learning model type TPS assisted by geogebra software, PBL learning model assisted by geogebra software, and DL learning model assisted by geogebra software with students' self confidence in mathematical problem solving ability.This research is a quasi-experimental research with a $3 \times 3$ factorial design. The population in this study were all students of class XI MIA which consisted of 7 classes, while the sample consisted of 3 classes with 103 students. Data were analyzed using two-way analysis of variance (Two Way Anova).
\end{abstract}

Keywords: Mathematical Prolem Solving, A TPS Cooperative Learning Model, A PBL Learning Model, DL Learning Model, Self Confidence, Geogebra Software.

\section{INTRODUCTION}

Indonesian education systems that are carried out in schools teach various disciplines, one of which is mathematics. Mathematics is the science that is taught from lower education to higher education. The essence of mathematical learning is learning to solve problems by using a deductive thought pattern Problem solving is one of the most important skills in school mathematics. According to Ratumanan and Laurens [1], math study is expected not only to lead students to a master of mathematical concepts (a larger mathematical object), but it will organize students' thinking abilities, problemsolving abilities, reasoning abilities, and other abilities.

Mathematical problem solving can be dealt with asa systematic nonroutine solution of problems by requiring previous knowledge to accomplish them [2]. Solving the problem is not only a target for learning mathematics but also a primary tool for doing study. In learning math, there are abilities that students must master [2].

The mathematical solutions encountered in students should be supported by the use of the learning model the teacher uses in the learning process. A cooperative learning model is one of the models used by math teachers in the teaching process to date. According to Ratumanan [3], cooperative learning is based on homini's social philosophy that emphasizes that humans are social creatures. As social creatures, cooperation is an important aspect of achieving a goal. Think pair share (polling) is one of the types of learning models of the cooperative learning model. [4] The cooperative learning model think pair share is one easily implemented cooperative learning model.

According to Ratumanan [3], a TPS cooperative learning model provides opportunities for students to work on their own and work with others. On the other hand, the model of learning that may affect the ability to solve current students' mathematical problems that is used on curriculum 2013 is the model for learning the problem based learning and the discovery learning model.

According to Arends [5], the model of learning problem based learning (PBL) is a learning approach, in which students work on authentic problems with the 
intent of building up their own knowledge, developing high levels of incubation and thinking skills, developing independence and confidence. Arends [3] also states that one of the aims of PBL learning is thinking skill and problem solving. This suggests that there is a link between an advanced model of the mathematical problem solving ability.

The discovery learning model (DL) is a learning model developed on the translation of the construction vism [3]. It also adds that specifically studying with the dl model trains the students' ability to find and solve math problems with or without the help of others. Thus there is a correlation between the DL learning model and the ability to solve mathematical problems. Regardless of the learning model a teacher uses, the use of the learning model must be adapted to the learning materials.

Sliced cone is one of the math materials on the math taught to the sophomores. The cone content taught at a high school level learns only the type of cone slice in a circle. This is in accordance with curriculum 2013 revision. [6] The content of the cone is essential to students' deep geometry concepts in order to know how the cone slices are formed and what kinds of cones are. Associated with the geometry concept teachers as teachers can use learning media assistance according to the technological development of the industrial revolution 4.0.

Geogebra software is one of the math software that can be used as a learning medium in learning geometry. According to Syahbana [6], geogebra software is one of the dynamic programs that have facilities to visualize or demonstrate mathematical concepts and as an aid to mathematical concepts. The use of geogebra software can increase conceptual and procedural knowledge [7]. Despite Syahbana and Siswanto views, the most important thing that can also influence students in receiving materials and achieving the purposes of learning is self confidence.

Self confidence is one of the corrective aspects of high school math purposes rather than a self defined learning and a math disposition. According to Aisyah [8], when a student with good problem solving ability he or she already has good insight ability and a high level of confidence. Thus that students' self confidence can also be affected the student's ability to solve the problem given by the teacher.

According to the results of the daily assessment of the sophomores at one of the fourth grade classes at state high school working on the teacher's problem. This shows the results of LK, RM, and VS students' work on one of the problems such as in the following Figure 1, Figure 2, and Figure 3.

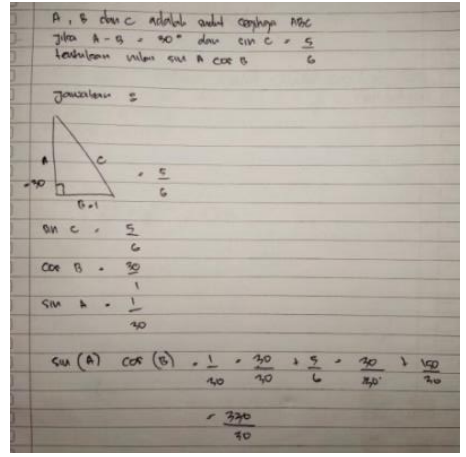

Figure 1.1 Of The LK Student Work

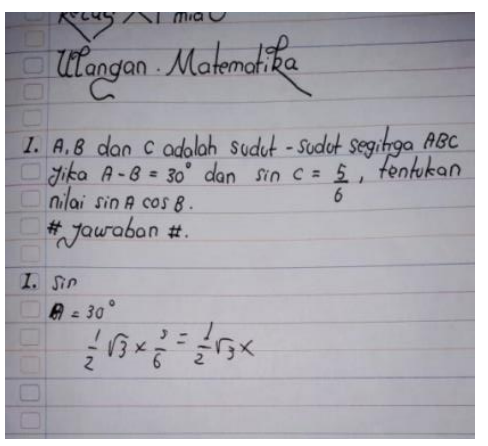

Figure 1.2 Of The RM Student Work

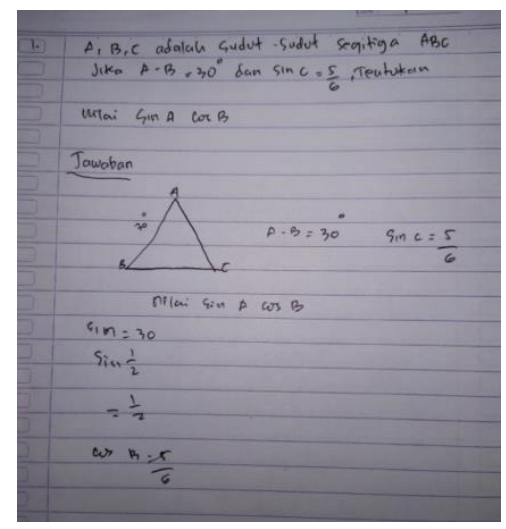

Figure 1.3 Of The VS Student Work

Judging from the Figure 1.1 student LK drawing the build of a triangle that is not consistent with the information of the problem, and it does not work according to the procedure of problem solving, thus causing the final answer to be either wrong or unable to correct the problem. In the Figure 1.2 RM students do not interpret a triangle but work the problem right away but the final answer given is wrong, whereas in the Figure 1.3 student VS does draw a triangle according to the information but in resolving the problem the $\mathrm{rm}$ student also answers incorrectly without good completion steps to solve a math problem.

Observations of teachers and students in the class are also made available by researchers. The learning process using a traditional model is still used by the teacher. This is pointed at teacher centered learning, so the media of learning that a teacher should use for teaching is not used for that. Students have 
found the students' self-confidence to be very low. This is indicated by the student's lack of confidence in completing the assignment the teacher gives during the learning process, resulting in a low degree of confidence in completing the teacher's daily assessment. These facts have also been strengthened by the 2012 work of the third international mathematics and science study [9], which states that the international scale is only $14 \%$ The students have a high self confidence, $45 \%$ Seeing as a workable self confidence student $41 \%$ A student with a low level self confidence regarding the mathematics. This is also true of Indonesian students, based on research for Martyanti [10], indicating that $3 \%$ a high confidence student $52 \%$ a self confidence student, $45 \%$ a student with a low level self confidence. Whereas according to Aisyha [8], to solve a student's math problem, one must understand the problem with great confidence. The conventional learning models and media employed in the learning process are not suitable for the student as well as causing a poorly informed ability and a low self confidence result in the student's low daily assessment.

A TPS, PBL, and an DL three comparable types of cooperative learning models are in relation to the mathematical problem solving capabilities and a self confidence student as set out above. The three models, researchers believe, with the learning media of geogebra software, can boost a confidence confidence in students to address a teacher's problem of sliced cone and thus result in students' learning to measure up well to the minimum criteria (KKM) set for the school.

Based on some of the fore going information, researchers would like to pursue a study entitled " Influence of the think pair share (TPS) cooperative learning model, Problem Based learning (PBL), and discovery learning (DL) Using a geogebra based software on the potential mathematical problem based on a self confidence student On the cone slices (experimental study in state high school 4 Ambon eleventh grade students). Based on the above background, the problem is defined in the study to (1) whether there is a difference between a TPS cooperative learning model with geogebra software, a PBL study model with geogebra software, and the dl learning model with geogebra software (2) whether there is a difference between the student with a high degree of self confidence and a low degree of self-awareness of the student's mathematical potential? and (3) whether there is an interaction between a TPS cooperative type with geogebra software, a gebra learning model with a gebra learning model and a dl view of geogebra solving capabilities?

\section{RESEARCH METHODS}

Method used in this research is a type of pseudo science. As for the design in this research, a three- vectorial design with a two way anova analysis technique. The design of this research is that;

Table 1. Design of This Research

\begin{tabular}{|l|c|c|c|}
\hline \multirow{2}{*}{$\begin{array}{l}\text { The learning } \\
\text { model }(\boldsymbol{A})\end{array}$} & \multicolumn{3}{|c|}{ Self Confidence (B) } \\
\cline { 2 - 4 } & High $\left(B_{1}\right)$ & Medium $\left(B_{2}\right)$ & Low $\left(B_{3}\right)$ \\
\hline $\operatorname{TPS}\left(A_{1}\right)$ & $\left(A_{1} B_{1}\right)$ & $\left(A_{1} B_{2}\right)$ & $\left(A_{1} B_{3}\right)$ \\
\hline $\operatorname{PBL}\left(A_{2}\right)$ & $\left(A_{2} B_{1}\right)$ & $\left(A_{2} B_{2}\right)$ & $\left(A_{2} B_{3}\right)$ \\
\hline $\operatorname{DL}\left(A_{3}\right)$ & $\left(A_{3} B_{1}\right)$ & $\left(A_{3} B_{2}\right)$ & $\left(A_{3} B_{3}\right)$ \\
\hline
\end{tabular}

Decription:

$\mathrm{A}_{1} \quad$ : A TPS cooperative learning model with geogebra software

$\mathrm{A}_{2} \quad$ : A PBL learning model with geogebra software

$\mathrm{A}_{3} \quad$ : A DL learning model with geogebra software

$\mathrm{B}_{1} \quad$ : Self confidence high

$\mathrm{B}_{2} \quad$ : Self confidence medium

$\mathrm{B}_{3}$ : Self confidence low

The study takes place at state high school 4 ambon. The time of the study was carried out in the school year's eventh-semester 2019/2020 And runs from January 20 to 2020 through February 19, 2020. The population in this study is all over the students eleventh grade in mathematics and natural sciences (MIA) and the total number of samples was 103 students. The students at XI MIA4 as an experiment 1 class using a TPS cooperative learning model with geogebra software, students at XI MIA2 as an experiment 2 class using the PBL study model with geogebra software, and students at XI MIA6 as an experiment 3 class using the DL study model with geogebra software.

The learning tools used in this study are the teaching materials (BA) and the student worksheet (LKS). Analysis of research data results from students' metamuatic problem solving on cone slices (circles and parabolas) and angket self confidence students. As for a descriptive data analysis of the student's mathematical problem solving ability using a benchmark assessment with five point conversion [1] show at the following Table 2.

Table 2. Benchmark Assessment

\begin{tabular}{|c|c|}
\hline Value Interval & Category \\
\hline $90 \leq x$ & Very high \\
\hline $75 \leq x<90$ & High \\
\hline $60 \leq x<75$ & Moderate \\
\hline $40 \leq x<60$ & Low \\
\hline$x<40$ & Very low \\
\hline
\end{tabular}

For an analysis of the data on self confidence using a three category category of self confidence, moderate, and low [11]. The classification is show at the following Table 3. 
Tabel 3. Self Confidence Category

\begin{tabular}{|l|l|c|}
\hline No & \multicolumn{1}{|c|}{ Criteria } & Category \\
\hline 1 & $x>(\mu+\sigma)$ & High \\
\hline 2 & $(\mu-\sigma) \leq x \leq(\mu+\sigma)$ & Moderate \\
\hline 3 & $x<(\mu-\sigma)$ & Low \\
\hline
\end{tabular}

This research began with teaching and learning activities in the three classes using the TPS type cooperative learning model assisted by geogebra software, PBL learning model assisted by geogebra software, and DL learning model assisted by geogebra software and the results obtained are:

\section{RESULTS AND DISCUSSION}

3.1 Students' Mathematical Problem Solving Ability

Tabel 4. Results of Students' Mathematical Problem Solving Ability

\begin{tabular}{|l|c|c|c|c|}
\hline \multirow{2}{*}{\multicolumn{1}{c|}{ Category }} & \multirow{2}{*}{ Value } & \multicolumn{3}{c|}{ Student Sum } \\
\cline { 3 - 5 } & & Experimen class 1 & Experimen class 2 & Experimen class 3 \\
\hline Very High & $90 \leq x$ & - & 3 & - \\
\hline High & $75 \leq x<90$ & 9 & 17 & 3 \\
\hline Moderate & $60 \leq x<75$ & 13 & 10 & 7 \\
\hline Low & $40 \leq x<60$ & 11 & 4 & 9 \\
\hline Very low & $x<40$ & 2 & - & 15 \\
\hline
\end{tabular}

Based on the Table 4, in the above shows that category 1 for experiment 1 and experiment 3 classes did not exist, whereas for experiment 2 experiment 2 there were 3 students. For high category grades in experiment class 1 there are 9 students, experiment class 2 there are 17 students, and experiment class 3 there are 3 students. For moderate grade in experiment class 1 there are 13 students, experiment class 2 has 17 students, and experiment class 3 has 7 students. For the low qualifications grade in experiment 1 there are 11 students, experiment class 2 there are 4 students, and experiment class 3 there are 15 students, while the grades in the extremely low category for experiment class 1 there are 2 people, experiment 2 class no, and experiment 3 experiment class 9 students.
3.2 Average Student Mathematical Problem Solving Ability

Table 5. Average Student Mathematical Problem Solving Ability

\begin{tabular}{|c|c|}
\hline Class & Average \\
\hline Experimen Class 1 & 65.99 \\
\hline Experimen Class 2 & 74.65 \\
\hline Experimen Class 3 & 51.04 \\
\hline
\end{tabular}

From Table 5, it appears that the average value of the student's mathematical problem solving capability is 2 larger than the student's average score in experiment 1 and experiment class 3 , which is that experiment 2 scored an average of 75.65, experiment class 1 scored an average of 65.99, and experiment class 3 scored an average of 51.04 .

\subsection{The Grouping Category Self Confidence Students}

Table 6. The Grouping Category Self Confidence Students

\begin{tabular}{|c|c|c|c|c|c|}
\hline \multirow{2}{*}{ Criteria } & \multirow{2}{*}{ Category } & \multirow{2}{*}{ Class } & \multirow{2}{*}{ Total } \\
\cline { 3 - 5 } & & Experiment 1 & \multirow{2}{*}{ Experiment 2 } & Experiment 3 & \\
\hline$x>107.99$ & High & 12 & 11 & - & 23 \\
\hline $72.02 \leq x \leq 107.99$ & Moderate & 12 & 18 & 11 & 41 \\
\hline$x<72.02$ & Low & 11 & 5 & 23 & 39 \\
\hline
\end{tabular}

From Table 6, it is evident that the overall rate of self confidence in 1 experiment class was 12 students, experiment 2 was 11 students, and experiment 3 was not available, so the total number of students gained a measure of self confidence as high as 23 students. Seeing me with a worse 1 experimental class of 12 students, a 2 experimental class of 18 students, and a 3 on an experiment class of 11 So the overall number of students increasing at a moderate rate of 41 . Self seeing in the low category of experiment 1 is 11 students, experiment 2 is 5 students, and experiment 3 is 23 students, bringing the total number of self seeing in the low category of 39 .
3.4 Normality Test

Table 7. Normality Test $(\alpha=0.05)$

\begin{tabular}{|c|l|l|l|}
\hline Date Group & Sig. & $\boldsymbol{\alpha}$ & Conclusion \\
\hline Experiment Class 1 & 0.067 & 0.05 & Accept $\mathrm{H}_{0}$ \\
\hline Experiment Class 2 & 0.186 & 0.05 & Accept $_{0}$ \\
\hline Experiment Class 3 & 0.200 & 0.05 & Accept $\mathrm{H}_{0}$ \\
\hline Self confidence high & 0.140 & 0.05 & Accept $_{0}$ \\
\hline Self confidence moderate & 0.121 & 0.05 & Accept $\mathrm{H}_{0}$ \\
\hline Self confidence low & 0.146 & 0.05 & Accept $\mathrm{H}_{0}$ \\
\hline
\end{tabular}


The above Table 7 , shows the sig value of each data group is greater than 0,067 , experiment 1 class of 0,186 , experiment class 2 of 0,200 , self confidence high of 0,140 , self confidence moderate of 0,121 , and self confidence low of 0,146 . Thus it could be concluded that $\mathrm{H}_{0}$ was accepted or in other words the six data groups were normal distribution.

3.5 Homogenity Test

Table 8. Homogenity Test $(\alpha=0.05)$

\begin{tabular}{|c|c|c|c|}
\hline Data Group & Sig. & $\boldsymbol{\alpha}$ & Conclusion \\
\hline Experiment Class 1 & & & \\
\cline { 1 - 1 } Experiment Class 2 & & & \\
\cline { 1 - 1 } Experiment Class 3 & \multirow{3}{*}{0.094} & 0.05 & \multirow{2}{*}{ Accept $\mathrm{H}_{0}$} \\
\cline { 1 - 1 } Self confidence high & & & \\
\cline { 1 - 2 } Self confidence moderate & & & \\
\cline { 1 - 2 } Self confidence low & & & \\
\hline
\end{tabular}

From the Table above it appears that a sig. greater than 0,094. This means H_0is accepted and denied H_1so it can be said that the variances of the six data groups are homogeneous. Thus, data analysis using the anova two way test can be used.

3.6 Hypothesis Test

Table 9. The results of the hypothetical test using the two way anova test $(\alpha=0.05)$

\begin{tabular}{lccc}
\multicolumn{1}{c}{ Data Grup } & Sig. & $\boldsymbol{\alpha}$ & Conculison \\
\hline $\begin{array}{l}\text { The cooperative learning } \\
\text { models with TPS, PBL, } \\
\text { and the DL with geogebra }\end{array}$ & 0.006 & 0.05 & Accept $\mathrm{H}_{0 \mathrm{~A}}$ \\
$\begin{array}{l}\text { software } \\
\begin{array}{l}\text { Self confidence high, Self } \\
\text { confidence moderate, and }\end{array}\end{array}$ & 0.000 & 0.05 & $\begin{array}{c}\text { Accept } \\
\mathrm{H}_{0 \mathrm{~B}}\end{array}$ \\
$\begin{array}{l}\text { Self confidence low } \\
\text { The interaction of a } \\
\text { learning model with a self } \\
\text { confidence }\end{array}$ & 0.285 & 0.05 & $\begin{array}{c}\text { Reject } \\
\mathrm{H}_{0 \mathrm{AB}}\end{array}$ \\
\hline
\end{tabular}

From Table 9,is obtained results that are (1) that a sig value. for the three learning models of 0,006 is less than value $\alpha=0,05$. This means that H_0A was rejected and that $\mathrm{H} \_1 \mathrm{~A}$ was accepted or could be said there is a difference between a TPS learning model with geogebra software, The PBL study with geogebra software, and the DL geogebra software assists against students' mathematically solving capabilities, (2) that a sig value on the three categories of self confidence is 0,000 times smaller than a comparable $\alpha=0,05$. This means that H_OB is rejected and H_1B is accepted or is arguably certain there is a difference between a high, moderate, and low self confidence in a student's mathematically challenged capabilities, and (3) that a sig value for a learning model interaction with a self confidence is a measure of 0,285 greater than a projected $\alpha=0,05$. This means that H_OAB ab is accepted and that H_1ABis denied or can be said that there is no interaction between a TPS cooperative study model with geogebra software, a PBL learning model with geogebra software, and the DL learning model with a self confidence in students' ability to solve mathematical problems.

3.7 Post Anova Multiple Comparison Test for Teaching Model

Table 10. Tuckey on Learning Models

\begin{tabular}{cccll}
\hline (I) Classes & $(\mathbf{J})$ Classes & $\begin{array}{c}\text { Mean } \\
\text { Difference } \\
(\mathbf{I}-\mathbf{J})\end{array}$ & $\begin{array}{l}\text { Std. } \\
\text { Error }\end{array}$ & Sig. \\
\hline $\begin{array}{c}\text { Experiment } \\
1\end{array}$ & $\begin{array}{c}\text { Experiment } \\
2\end{array}$ & $-8.6609^{*}$ & 2.10851 & .000 \\
& $\begin{array}{c}\text { Experiment } \\
3\end{array}$ & $14.9473^{*}$ & 2.10851 & .000 \\
$\begin{array}{c}\text { Experiment } \\
1\end{array}$ & $8.6609^{*}$ & 2.10851 & .000 \\
2 & $\begin{array}{c}\text { Experiment } \\
3\end{array}$ & $23.6082^{*}$ & 2.12374 & .000 \\
$\begin{array}{c}\text { Experiment } \\
1\end{array}$ & $-14.9473^{*}$ & 2.10851 & .000 \\
3 & $\begin{array}{c}\text { Eksperimen } \\
2\end{array}$ & $-23.6082^{*}$ & 2.12374 & .000 \\
\hline
\end{tabular}

Based on Table 10, it appears that there is a significant difference between experiment 1 class, experiment 2 class, and experiment 3's ability to solve mathematical problems. The student's mathematical problem solving ability on experiment 2 classes taught with a geogebra learning model is better than a 1 experiment class taught with a TPS cooperative learning model with geogebra software and experiment 3 being taught with the dl study model with geogebra software. This is shown in the difference between experiment 2 and experiment class 1 in $8,6609^{*}$ or experiment class 2 was 2 less than the estimated $\alpha=0,05$, that is, 0,000 and experiment 2 and experiment class 3 were different $23,6082 *$ or the sig. Experiment class 2 is less than the estimated $\alpha=0,05$, which is 0,000 . Significant differences also existed in experiment 1 and experiment 3 classes. The ability to solve the student's mathematical problems in experiment 1 class is better than the student in experiment 3. This is shown in the difference between the eskperimen 1 and experiment 3 class of $14,9473 *$ or the sig. experiment class 1 is smaller than the estimated $\alpha=0,05$, which is 0,000 . Thus the ability to solve a student's mathematical problem on experiment 1 class taught with a TPS cooperative learning model helped with geogebra software better than the students in experiment 3 being taught with the DL learning model with geogebra software. 
3.8 Post Anova Multiple Comparison Test for Self Confidence

Table 11. Tuckey on Self Confidence

\begin{tabular}{|c|c|c|c|c|}
\hline $\begin{array}{l}\text { (I) } \\
\text { Category } \\
\text { Self } \\
\text { Confidence }\end{array}$ & $\begin{array}{c}(\mathbf{J}) \\
\text { Category } \\
\text { Self } \\
\text { Confidence }\end{array}$ & $\begin{array}{c}\text { Mean } \\
\text { Differenc } \\
\text { e (I-J) }\end{array}$ & $\begin{array}{l}\text { Std. } \\
\text { Error }\end{array}$ & Sig. \\
\hline \multirow{2}{*}{ High } & Moderate & $15.8346^{*}$ & 2.28118 & 0.000 \\
\hline & Low & $36.3023 *$ & 2.30210 & 0.000 \\
\hline \multirow{2}{*}{ Moderate } & High & $-15.8346^{*}$ & 2.28118 & 0.000 \\
\hline & Low & $20.4677 *$ & 1.95860 & 0.000 \\
\hline \multirow{2}{*}{ Low } & High & $-36.3023 *$ & 2.30210 & 0.000 \\
\hline & Moderate & $-20.4677 *$ & 1.95860 & 0.000 \\
\hline
\end{tabular}

From the Table 11 above, it can be seen that the difference between students who have high self confidence against students who have moderate and low self confidence is $15,8346^{*}$ and $36,3023^{*}$, respectively. This is clarified by the Sig value of 0,000 which is smaller than the value of $\alpha=0,05$, so in other words there are significant differences in students' mathematical problem solving abilities between students who have high, moderate, and low self confidence. Thus it can be concluded that the mathematical problem solving abilities of students who have high self confidence are better than students who have moderate and high self confidence. A significant difference also occurs in students who have moderate self confidence with students who have low self confidence. This is indicated by the difference value of $20,4677 *$ or the Sig value of 0,000 , which is smaller than the value of $\alpha=0,05$. This means that the mathematical solving abilities of students who have moderate self confidence are better than students who have low self confidence.

3.9 Students' Mathematical Problem Solving Ability Using Cooperative Learning Model Type TPS Assisted by Geogebra Software

In experiment 1 class, teachers used a TPS cooperative learning model with geogebra software. The learning process begins by greeting, conveying the purpose of learning and referencing related material using software Geogebra to students. At the meeting of all couples in the group noticed an explanation by the teacher using geogebra software. The use of digital media of geogebra software in the math learning used by teachers can have a positive effect on students in the learning process. It is as suggested by voogt [12], that the use of technology can affect the content and purpose of learning, and as a medium to improve the teaching process.

The teacher then divides the students in groups and gives the LKS to each group to work on. At the think and pair stage all working groups follow that step at all meetings. For the share stage there are only a few groups that carry it out at each meeting (appendix 6a). This is in accordance with the student activity in the share step which is only done by a few groups [3]. At the LKS completion in each group the teacher gives the materials to help students solve problems at all meetings. It's very helpful for the students to solve the problem with the LKS.

After the learning process in experiment class 1 using a type-type cooperative learning model during 8 meetings and at the 9th meeting, the teacher gives a final test to measure the students' ability to solve mathematical problems. Results indicate that the ability to solve the student's mathematical problem with the high value category is not present, the high rating category is 9 students, the grade category is 13 , the low value category is 11 students, and the rating category is low to 2 students.

\subsection{Students' Mathematical Problem Solving Ability} Using Geogebra Software Assisted PBL Learning Model

On experiment 2 class, the learning model used is a PBL learning model. The study activity in this class lasted for 8 meetings and Plus one meeting for the final test. Each teacher meeting divides students into groups of 4-5. At all meetings it appears that all the group members observe the issue of the LKS and discuss how the problem with the LKS is solved by them. Students also note the explanation with the teacher using geogebra software (appendix 6b).

The use of the geogebra software used by the teacher greatly helps students understand the material and solve mathematical problems. This accords with the kind of geogebra software presented by Nur [13] as a medium of mathematics study, a mathematical tool, and a mathematical solution. On the other hand, the LKS given by teachers to students are contextual problems consistent with conical slice materials in circles and parabolas. This is in accordance with the characteristic of the PBL learning model presented by Oktaviani etc [14] that students are faced with a problem that relates to the real world and is solved in groups.

After the teacher has completed the learning process during the 8 meetings, the teacher then gives the final test to quantify the students' ability to solve mathematical problems. Based on results obtained and analyzed, it shows the ability to solve the student's mathematical problems at the high value category to 3 students, the high value category to 17 students, the value category to 10 students, the low value category to 4 students, and the extremely low value category to no.

\subsection{Students' Mathematical Problem Solving Ability}

Using Geogebra Software Assisted DL Learning Model

DL learning model. The learning process in the class is carried out during 8 meetings. At each teacher meeting the class divides students into groups of 4-5. The learning process at meeting 1 is shown that group members from several groups do not observe the 
teaching materials given by the teacher to complete the LKS in each group. It also happens during meetings 2 through 8, when Widodo and Jasmin [15] one function of the lesson is to help students learn something. On the other hand, at the 4th meeting not all members of the group discuss to settle the issue with the teacher. This causes group members who have discussions to understand the material better. This is clarified by Suryana [16], which states that the DL learning model gives students the opportunity to work together in groups to solve the teacher's problem so that all group members can understand the material presented after resolving the problem.

At the 9 teacher meeting gave a test to the student to measure the student's ability to solve mathematical problems. Based on the data obtained and analyzed (appendix 11c) suggests that the students' ability to solve mathematical problems in experiment class 3 in the high value category does not exist, the high value category amounts to 3 students, the high value category amounts to 7 students, the low value category amounts to 15 students, and the rating category falls to 9 students.

3.12Students' Mathematical Problem Solving Ability Using Cooperative Learning Model Type TPS Assisted by Geogebra Software, Geogebra Software Assisted PBL Learning Model, and Geogebra Software Assisted Learning DL Model in terms of Self Confidence

Overall at meeting 9 in each class the teacher gave a final test to students to measure their mathematical problem solving abilities and a self confidence questionnaire to find out the level of self confidence of the student. The results of the tests and questionnaires obtained are then processed and analyzed to determine whether there are differences in mathematical problem solving abilities based on the TPS type cooperative learning model assisted by geogebra software, PBL learning model assisted by geogebra software, DL learning model assisted by geogebra software and based on high, moderate, high self confidence, and low and whether there is an interaction between learning models and self confidence. The results of the normality test as a prerequisite test for analysis with SPSS 19.0 indicate that the six groups of data come from normal samples because of the Sig. in the six groups the value was greater than $\alpha=0,05$. The second prerequisite test conducted was to test the population homogeneity of the six data and the Sig. 0,094 is greater than the value of $\alpha=0,05$, so that H_0 is accepted and H_ 1 is rejected or in other words the population is homogeneous.

Based on the prerequisite test that has been met, then the hypothesis testing uses the Two Way Anova test. The results of the hypothesis test show that there are differences in the mathematical problem solving abilities of students who are taught with the TPS type cooperative learning model assisted by geogebra software, PBL learning model assisted with geogebra software, and DL learning model assisted by geogebra software. This can be seen in the Sig. equal to 0,006 smaller than the value of $\alpha=0,05$. Differences in mathematical problem solving abilities were also found in students who had high, medium, and low self confidence due to the Sig. equal to 0,000 which is smaller than the value of $\alpha=0,05$. Another result also shows that there is no interaction effect between the TPS type cooperative learning model assisted by geogebra software, PBL learning model assisted by geogebra software, DL learning model assisted geogebra software with student self confidence, because the Sig. equal to 0,285 which is greater than the value of $\alpha=0,05$. This is because students' self confidence does not imply choosing a cooperative learning model type TPS assisted by geogebra software, PBL learning model assisted by geogebra software, and DL learning model assisted by geogebra software, but whether or not the three learning models are determined by student learning outcomes in the form of ability Mathematical problem solving is also reinforced by the results of Ainun's research [17], which states that the affective aspects of students do not imply choosing a particular model, but whether or not a learning model is appropriate is determined by student learning outcomes.

The followup test with the Tuckey test in this study was used to determine significant differences in mathematical problem solving abilities based on the learning model, namely the TPS cooperative learning model, the PBL learning model, the DL learning model assisted by geogebra software, and based on high, moderate, and low selfconfidence. Further test results show that there are significant differences in mathematical problem solving abilities between the TPS type cooperative learning model, PBL learning model, and geogebra software assisted DL learning model where the geogebra software assisted PBL learning model is better than the geogebra software assisted TPS type cooperative learning model and geogebra software assisted DL learning model. This is because the Mean Difference value of the PBL learning model to the TPS cooperative learning model is $8,6609 *$ and the Mean Difference value of the PBL learning model to the DL learning model is $23,6082 *$. This result is reinforced by the results of previous research from Hasibun and Sinaga [18], which states that the mathematical problem solving abilities of students taught with the PBL learning model are better than students taught with the DL learning model and Aisyah's research results [8], which states that the mathematical problem solving abilities of students who are taught with the geogebra software-assisted PBL learning model are better than those taught with the TPS type cooperative learning model assisted with geogebra software.

The Mean Difference value of students who have high self confidence towards students who have moderate self confidence is $15,8346 *$ and the Mean 
Difference value of students who have high self confidence against students who have low self confidence is $36,3023 *$. Based on the Mean Difference value, it can be concluded that the mathematical problem solving abilities of students who have high self confidence are better than students who have moderate and low self confidence. These results are reinforced by the results of research by Dewi and Minarti [19], which state that students who have high self confidence have good mathematical problem solving abilities than students who have moderate and low self confidence.

\section{Weaknesses of Research}

In this study, there are weaknesses because of the limitations of the researcher. This weakness is that the control class uses the DL learning model assisted by geogebra software, so that an error occurs in this study. Research errors occurred because researchers were not careful in planning the control class by including the use of geogebra software, which should not involve the use of geogebra software in the control class, so that the control class in this study was replaced with the experimental class 3 .

\section{CONCLUSION}

Based on data analysis and research discussions, it can be concluded that:

a. There isa difference in students' mathematical problem solving capability using a TPS cooperative learning model with geogbera software, a PBL learning model with geogbera software, and the dl learning model with geogbera software on the cone incision material of senior high school 4 Ambon.

b. There isa difference in the range of mathematical problem solving of the student who has a high, medium, and low in the cone - cut matter of a circle and a parabola in 4 state high school sains school 4 Ambon.

c. There is no interaction between a cooperative learning model a TPS cooperative with a geogbera software help, a PBL learning model with geogbera software, and a dl learning model with a geogbera software with a self confidence confidence in a student's mathematical problem solving capability.

\section{REFERENCES}

[1] Ratumanan, T. G., \& Laurens, T. 2015. Assessment of Learning Outcomes at the Level of Educational Units 3rd Edition. Yogyakarta: Communication Pencils.

[2] Nurrohmat \& et al. 2019. The Effect of Guided Invention Learning on Students' Mathematical Problem Solving Ability in terms of Initial Mathematical Ability. USAT Journal of Mathematics Education. Vol 12 No.2, pp. 211223.
[3] Ratumanan. T. G. 2015. Learning Innovation (Optimally Developing Student Competencies). Yogyakarta: Waves..

[4] Widianti, Hartini S., \& Aisah, L. S. 2018. Differences in Students' Mathematical Problem Solving Ability Using Two Stay Two Stray Cooperative Learning Model with Think Pair Share Type. Emasains Journal. Vol. 7. No.2, pp. 155-161.

[5] Putri, S.R. Suryani, M. \& Jufri, L.H. 2019. The Effect of the Application of the Problem Based Learning Model on Students' Mathematical Problem Solving Ability. Moshrafa: Journal of Mathematics Education. Vol. 8. No. 2, pp. 331340.

[6] Lekitoo. J. N., Moma. L., \& Ngilawajan. D. A. 2018. Improved Learning Outcomes of Class XI Students of SMA Negeri 4 Ambon on Cone Slices Using the Cooperative Learning Model through the Geogebra Software Assisted CAI (Computer Assisted Instruction) Learning Media. JUPITEK, Journal of Mathematics Education Unpatti. Vol. 1 No. 1, pp. 44-56.

[7] Siswanto, R. 2014. Improving Mathematical Reasoning and Communication Ability through the Application of Geogebra Software Assisted STAD Type Cooperative Learning Model (Experimental Study at SMAN 1 Cikulur, Lebak Regency, Banten Province). Journal of Education and Teacher Training. Vol. 1. No. 1, pp. 1-11.

[8] Aisyah. N. Effect of Geogebra Software Assisted Problem Based Learning Model on Mathematical Problem Solving Ability. JKPM. Vol. 1, No. 2, pp. 159-168.

[9] Nurkhofila, S., Toheri, \& Winarso, W. 2018. The relationship between Self Confidence and Students' Christian Thinking Ability in Mathematics Learning. EDUMATICA. Journal of Mathematics Education. Vol. 8, No. 1, pp. 58-66.

[10] Martyanti, A. 2013. The effectiveness of the Problem Solving Approach with $\neg$ Setting STAD and TAI in terms of achievement and selfconfidence. Journal of Mathematics Education Research. Vol. 3, No. 1, pp. 1-15.

[11] Ismail. 2017. The Influence Of Learning Approach Toward Learning Outcomes In Mathematics Based Prior Ability And Self Confidence Of Grade VII Students At SMPN 6 Moncongloe In Maros District. Journal of Mathematical Power. Vol. 5. No. 2, pp. 91-104.

[12] Budiman, H. \& Ramdhani, S. 2017. Development of Geogebra-Based High School Mathematics Teaching Materials for Android Version. Journal of Science Tech. Vol. 3 No. 2, pp. $75-80$.

[13] Nur, I. M. 2016. Utilization of Geogebra Program in Mathematics Learning. Journal of Mathematics and Mathematics Education. Vol. 5 No. 1 pp. 10-19. 
[14] Oktaviani, B. A. Y., Marwafi, \& Astuti, S. 2018. Differences in Problem Based Learning and Discovery Learning Models in terms of Mathematics Learning Outcomes of Grade 4 Elementary School Students. Journal of Education and Culture. Vol. 8 No. 2, pp. 132141

[15] Guntur, M., Muchyidin, A., \& Winarso, W. 2017. The Influence of Comic-Supplied Mathematics Teaching Materials on Student Learning Independence. EduMa Journal. Vol. 6 No. 1, pg. 43-54.

[16] Suryana, M. F. 2018. Efforts to Improve Learning Achievement of Quadrilateral Building Materials Through the Discovery Learning Model for Class VII C Students of SMP Negeri 3 Teras Boyolali Regency Even Semester of 2017/2018 Academic Year. Journal of Varia Pendidikan. Vol. 30 No. 1, pp. 47-61.

[17] Ainun, M. 2018. The Effect of the Application of Cooperative Learning Model Type Number Heads Togheter, Think Pair Share, and Think Pair Number Heads Togheter on Mathematics Learning Outcomes in terms of Initial Ability and Self Efficacy of Class VIII Students of State Junior High Schools in Sinjai Regency. Journal of Mathematical Education UNM. Vol 3. No. 2, pp. 1-11.

[18] Hasibun, R. \& Sinaga, B. 2017. Differences in Mathematical Problem Solving Ability Using Problem Based Learning and Discovery Learning Models in Class VIII of SMP Negeri 1 Percut Sei Tuan. Inspirational Journal. Vol. 3 No. 1, pp. 17-28.

[19] Dewi, S. N. \& Minarti, E. D. 2018. The Relationship Between Self-Confidence in Mathematics and Students' Problem Solving Ability on Circle Material. Mosharafa: Journal of Mathematics Education. Vol. 7 No.2, pp. 189-198. 